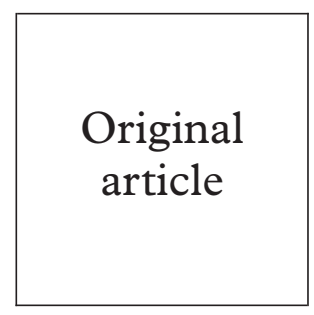

\title{
Sexually transmitted infections and risk behaviours in women who have sex with women
}

\author{
Katherine Fethers, Caron Marks, Adrian Mindel, Claudia S Estcourt
}

Objectives: To assess the prevalence of sexually transmitted infections (STIs) and blood borne viruses, risk behaviours, and demographics in women who have sex with women (WSW).

Methods: Retrospective cross sectional study using a multivariate model. Demographic, behavioural, and morbidity data were analysed from standardised medical records of patients attending a public STI and HIV service in Sydney between March 1991 and December 1998. All women with any history of sex with a woman were compared with women who denied ever having sex with another woman (controls).

Results: 1408 WSW and 1423 controls were included in the study. Bacterial vaginosis (BV) was significantly more common among WSW (OR 1.7, p<0.001). Abnormalities on cervical cytology were equally prevalent in both groups, except for the higher cytological BV detection rate in WSW (OR 5.3, p=0.003). Genital herpes and genital warts were common in both groups, although warts were significantly less common in WSW (OR $0.7, \mathrm{p}=0.001$ ). Prevalence of gonorrhoea and chlamydia were low and there were no differences between the groups. The prevalence of hepatitis C was significantly greater in WSW (OR 7.7, p<0.001), consistent with the more frequent history of injecting drug use in this group (OR 8.0, p<0.001). WSW were more likely to report previous sexual contact with a homo/bisexual man (OR 3.4, p<0.001), or with an injecting drug user (OR 4.2, $\mathrm{p}<0.001$ ). Only $7 \%$ of the WSW reported never having had sexual contact with a male.

Conclusion: We demonstrated a higher prevalence of BV, hepatitis C, and HIV risk behaviours in WSW compared with controls. A similar prevalence of cervical cytology abnormalities was found in both groups. Measures are required to improve our understanding of STI/HIV transmission dynamics in WSW, to facilitate better health service provision and targeted education initiatives.

(Sex Transm Inf 2000;76:345-349)

Keywords: sexually transmitted infections; lesbians; HIV

\section{Introduction}

The sexual health risks of women who have sex with women (WSW) are poorly understood. Traditionally, WSW have been perceived as a low risk group and have been largely overlooked in sexually transmitted infection (STI) and cervical cytology screening initiatives and risk intervention programmes. Misconceptions may be held by the healthcare providers and WSW, and this may have an impact on health status.

Most published studies of STI/HIV prevalence and risk behaviours in women have not considered WSW as a separate group. Those studies that have included WSW often lack information on specific sexual practices, have nearly always used convenience samples, and inconsistently define WSW by sexual identity or behaviour. ${ }^{12}$ This has led to a lack of understanding of STI/HIV transmission dynamics and behaviour of these women. However, the available data strongly suggest that WSW may demonstrate considerable sexual and nonsexual risk taking behaviours. ${ }^{2-7}$

We were concerned that the lack of knowledge of the sexual and behavioural characteristics and STI prevalence of WSW in Australia may adversely influence their health care. We designed a study to better understand the sexual health risks and needs of WSW.

\section{Methods}

Subjects included all women who reported ever having sex with a woman (WSW), who first attended Sydney Sexual Health Centre from 1 March 1991 to 31 December 1998 ( $n=1432)$. The Sydney Sexual Health Centre is a public inner city STI and HIV service in the central business district.

In order to obtain more information on women whose current sexual behaviour relates exclusively to sex with women, we defined a subgroup of women "exclusive WSW" ( $n=283$ of 1432 total WSW). Exclusive WSW were WSW who reported no sexual contact with a male in the past 12 months. This group was compared with the control group for demographic, behavioural, and morbidity variables.

Controls were women who reported never having had sex with another woman and who first attended Sydney Sexual Health Centre over the same time period. The next attending eligible woman was selected $(n=1423)$.

Clients attending "special" services at the centre (colposcopy, counselling, clinics for individual ethnic groups) were excluded from the study to avoid a potential source of selection bias as these clinics do not use the standard clinic case note documentation and/or service a very specific patient population. 
New clients attending SSHC are routinely offered a sexual health screen which includes tests for cervical Neisseria gonorrhoeae (Gram stain, culture) and Chlamydia trachomatis (cell culture from 1991 to 1995 and from then on by polymerase chain reaction), Trichomonas vaginalis (wet preparation of high vaginal swab), Candida species (Gram stain and culture as clinically indicated), and bacterial vaginosis (BV) diagnosed by Amsel's criteria ${ }^{3}$ or on cervical cytology. ${ }^{8}$ Routine cytology is recommended biannually to women who have been "sexually active". No specific recommendations are made for WSW. Genital herpes is diagnosed clinically and/or by culture. Genital warts are diagnosed clinically. Serological testing for hepatitis B, HIV, and syphilis are offered to all patients. From 1992, all patients who reported risk behaviour for hepatitis $\mathrm{C}$ acquisition were offered antibody testing.

Data were collected from standardised medical records that are routinely used for all clients attending the clinic. Data were extracted on a range of variables including age, ethnicity, sexual history, reason for presentation, symptoms, investigations, and diagnoses. These data were entered onto the clinic database soon after the time of presentation. Data were retrieved for the study from the database retrospectively.

In this retrospective cross sectional study, two sets of comparisons were made: WSW and controls, and exclusive WSW and controls. Comparisons between the groups were assessed using a $\chi^{2}$ test for categorical variables or the Fisher's exact test when required. Crude odds ratio (OR) with their $95 \%$ confidence intervals were calculated in a univariate analysis to compare study factors between all WSW and controls, and again in a subanalysis of exclusive WSW and controls. Factors found to be significant on univariate analysis at $\mathrm{p}<0.001$, or considered to be important confounding factors from the published literature, were further analysed using unconditional logistic regression models to permit the identification of independent variables $(p<0.05$ on multivariate analysis). The variables included in multivariate analysis were: age, bacterial vaginosis, hepatitis $\mathrm{C}$ infection, hepatitis $\mathrm{B}$ infection, genital warts, injecting drug use, sexual contact with a homo/bisexual man, sexual contact with an injecting drug user, number of male sexual partners, tobacco use, and history of termination of pregnancy. A check was performed before logistic regression to exclude high correlation between variables. Statistical analysis was performed using SPSS ${ }^{9}$ and SAs. ${ }^{10}$

This study was approved by the South Eastern Sydney Area Health Service research ethics committee.

\section{Results}

In all, 1432 women who reported ever having sex with another woman first attended Sydney Sexual Health Centre between 1 March 1991 and 31 December 1998. This represents $9.6 \%$ (14 899) of total new female registrations over this period; 283 were exclusive WSW. Four transsexual WSW were excluded from the analysis and 20 sex worker WSW, who reported sexual contact with women at work only, were also excluded.

DEMOGRAPHIC CHARACTERISTICS (ALL WSW) The median age of the WSW was 27 years (range 14-56) and this was not significantly different from controls (median 26, range 16-78). The groups differed in their ethnic composition, with the WSW significantly more likely to identify as Aboriginal or Torres Strait Islander ( $1 \%$ versus $<1 \%$, OR $3.8, \mathrm{p}=0.011)$, more likely to be born in Australia (65\% versus $52 \%$, OR 1.7, p<0.001), and more likely to speak English as their first language (94\% versus $88 \%$, OR $2.3, \mathrm{p}<0.001)$. Sixty three per cent of WSW and $66 \%$ of controls reported currently being in a sexual relationship and this difference was not significant.

WSW were less likely to have been referred by a general practitioner than controls $(6 \%$ versus $8 \%$, OR $0.7, \mathrm{p}=0.029)$; furthermore, WSW were significantly less likely to report genital symptoms as the reason for presentation $(19 \%$ versus $23 \%$, OR $0.8, p=0.003)$ and more likely to present requesting a Pap smear ( $7 \%$ versus $5 \%$, OR $1.4, \mathrm{p}=0.030)$.

PREVALENCE OF STI, HIV, AND RELATED CONDITIONS (ALL WSW)

Results presented are from univariate analysis (table 1). Bacterial vaginosis (BV) was significantly more common among WSW than controls both on diagnosis by Amsel's criteria (OR 1.7, p<0.001) and by cervical cytology ( $5 \%$ versus $1 \%$, OR 5.3, $\mathrm{p}=0.003)$. Gonorrhoea and chlamydia were uncommon and there was no significant difference in the prevalence of infection diagnosed in both groups. Clinical warts were diagnosed less often in WSW; however, WSW were significantly more likely to report a previous diagnosis of clinical warts than controls $(22 \%$ versus $15 \%$, OR $1.5, \mathrm{p}<0.001)$. There was a marked difference in the prevalence of hepatitis $\mathrm{C}$ with WSW more likely to be hepatitis $\mathrm{C}$ antibody positive than controls. Hepatitis B was also significantly more common among WSW. HIV was uncommon in both groups. There were five HIV positive WSW and three HIV positive controls. Forty four per cent of WSW reported a previous diagnosis of one or more STI, compared with $32 \%$ of the controls $(\mathrm{p}<0.001)$

On multivariate analysis, BV (OR 1.5) and new clinical warts (OR 0.7) (negative association) were the only two diagnoses shown to be independently associated with WSW.

CERVICAL CYTOLOGY

Information on cervical cytology was available from 1995 only. This included cytology from 356 WSW and 286 controls. There was no difference in the prevalence of abnormal cervical cytology and changes suggestive of cervical intraepithelial neoplasia (CIN 1, CIN 2-3) were equally prevalent in WSW and controls. 
Table 1. Demographics, STI detected at clinic visit, and risk behaviour comparing WSW and controls-results of univariate analysis

\begin{tabular}{|c|c|c|c|c|}
\hline & WSW (1408) & Controls (1423) & $\begin{array}{l}\text { Odds ratio and } \\
95 \% \text { CI }\end{array}$ & $p$ Value \\
\hline Age median (range) & $27(14-78)$ & $26(16-56)$ & & 0.77 \\
\hline Bacterial vaginosis & $111 / 1408(8 \%)$ & $69 / 1423(5 \%)$ & $1.7(1.2-2.3)$ & 0.001 \\
\hline Genital herpes & $133 / 1408(9 \%)$ & $136 / 1423(9 \%)$ & & 0.95 \\
\hline Genital warts & $106 / 1408(8 \%)$ & $158 / 1423(11 \%)$ & $0.7(0.5-0.9)$ & 0.001 \\
\hline Gonorrhoea & $4 / 958(<1 \%)$ & $7 / 888(<1 \%)$ & & 0.39 \\
\hline Chlamydia & $23 / 830(3 \%)$ & $31 / 747(4 \%)$ & & 0.34 \\
\hline Candida & $116 / 913(13 \%)$ & $142 / 867(16 \%)$ & & 0.12 \\
\hline Hepatitis C† & $73 / 1408(5 \%)$ & $10 / 1423(<1 \%)$ & $7.7(3.9-16.0)$ & $<0.001$ \\
\hline Hepatitis $\mathrm{B} \dagger$ & $73 / 1408(5 \%)$ & $36 / 1423(3 \%)$ & $2.1(1.4-3.2)$ & $<0.001$ \\
\hline HIV† & $5(<1 \%)$ & $3(<1 \%)$ & & 0.51 \\
\hline Abnormal cervical cytology $\ddagger$ & $69 / 356(19 \%)$ & $58 / 286(20 \%)$ & & 0.78 \\
\hline Past history of STIs ${ }^{\star}$ & $616 / 1408(44 \%)$ & $459 / 1423(32 \%)$ & $1.6(1.1-2.0)$ & $<0.001$ \\
\hline Sexual contact with homo/bisexual man & $206 / 1347(15 \%)$ & $68 / 1343(5 \%)$ & $3.4(2.5-4.6)$ & $<0.001$ \\
\hline $\begin{array}{l}\text { Sexual contact with heterosexual man with } \\
\text { multiple partners }\end{array}$ & $273 / 1408(19 \%)$ & $244 / 1423(17 \%)$ & & 0.13 \\
\hline Sexual contact with injecting drug user & $288 / 1353(21 \%)$ & $81 / 1346(6 \%)$ & $4.2(3.2-5.5)$ & $<0.001$ \\
\hline Smoker & $694 / 1408(49 \%)$ & $546 / 1423(38 \%)$ & $1.6(1.3-1.8)$ & $<0.001$ \\
\hline More than $140 \mathrm{~g}$ alcohol per week & $172 / 1408(12 \%)$ & $143 / 1423(10 \%)$ & & 0.07 \\
\hline Injecting drug use (ever) & $316 / 1398(23 \%)$ & $49 / 1387(4 \%)$ & $8.0(5.6-11.3)$ & $<0.001$ \\
\hline Sex worker (current) & $235 / 1089(22 \%)$ & $114 / 1061(11 \%)$ & $2.3(1.8-2.9)$ & $<0.001$ \\
\hline Termination of pregnancy in past & $537 / 1408(38 \%)$ & $380 / 1423(27 \%)$ & $1.7(1.4-2.0)$ & $<0.001$ \\
\hline
\end{tabular}

tPrevious and new diagnoses.

$\ddagger$ Refers to cervical atypia, and CIN1-3.

${ }^{\star}$ Self reported previous history of $N$ gonorrhoeae, bacterial vaginosis, syphilis, genital herpes, genital warts, or $C$ trachomatis.

PREVALENCE OF STI, HIV, AND RELATED

CONDITIONS IN EXCLUSIVE WSW

Ten per cent of exclusive WSW were diagnosed with BV on first attendance and there was a greater disparity in the prevalence of $\mathrm{BV}$ detected in exclusive WSW and controls $(10 \%$ versus $5 \%$, OR $2.2, \mathrm{p}=0.002$ ) than the WSW group as a whole (table 1). In addition, exclusive WSW were significantly less likely than controls to have a Gram stain or wet film ( $48 \%$ versus $61 \%$, OR $0.6, \mathrm{p}<0.001)$, making detection of asymptomatic BV less likely in exclusive WSW.

The prevalence of hepatitis C in exclusive WSW was similar to that in all WSW. Hepatitis $\mathrm{B}$ was also more common in exclusive WSW compared with controls. Three exclusive WSW were HIV positive (1\%). One case of Trichomonas vaginalis and three cases of chlamydia were diagnosed in exclusive WSW. There was no difference in the prevalence of abnormal cervical cytology results between exclusive WSW and controls.

SEXUAL RISK BEHAVIOUR (ALL WSW)

Ninety three per cent of WSW reported previous sexual contact with a man. Interestingly, the median number of lifetime male sexual partners was significantly greater for WSW than controls $(12$ partners versus $6, \mathrm{p}<0.001)$. WSW were significantly more likely to report more than 50 lifetime male sexual partners ( $9 \%$ versus $2 \%$, OR $4.1, p<0.001)$. Eighty per cent of the WSW reported five or fewer female lifetime partners and $8 \%$ reported more than 10 lifetime female partners.

Sexual contact with a homosexual or bisexual man and sexual contact with an injecting drug user (IDU) were both significantly more common among WSW. There was no significant difference between the groups in reported sexual contact with a heterosexual man with multiple partners. Sex work was significantly more common in WSW (table 1).

History of pregnancy, and termination of pregnancy (TOP) in particular, were more common in WSW (52\% versus $44 \%$ and $38 \%$ versus $27 \%$ respectively, $\mathrm{p}<0.001)$.

On multivariate analysis, factors which were shown to be independently associated with WSW were sexual contact with a homosexual or bisexual man (OR 2.5), sexual contact with an IDU (OR 2.1), more than 50 lifetime male sexual contacts (OR 3.4), and previous TOP (OR 1.4).

EXCLUSIVE WSW SEXUAL RISK BEHAVIOUR

Twenty five per cent reported no previous sexual contact with men ever. However, exclusive WSW were still significantly more likely than controls to report more than 50 lifetime male sexual partners ( $4 \%$ versus $2 \%$, OR 2.8 , $\mathrm{p}=0.003)$.

The risk behaviour profile of exclusive WSW was similar to all WSW: they were significantly more likely to report past sexual contact with a homosexual or bisexual man and sexual contact with an IDU. The exclusive WSW were less likely than controls to report sexual contact with a heterosexual man with multiple partners. Unlike the WSW group as a whole, exclusive WSW were less likely than controls to report a previous TOP (18\% versus $27 \%$, OR $0.6, \mathrm{p}=0.002$ ).

NON-SEXUAL RISK BEHAVIOUR (ALL WSW)

There was a marked difference in reported rates of injecting drug use between the groups. Twenty three per cent of WSW reported current or previous injecting drug use, compared with $4 \%$ of the control group. WSW were significantly more likely to smoke than controls and this difference increased when looking at the rates of heavy smoking - that is, more than 20 per day $(18 \%$ versus $11 \%$, OR 1.7 , $\mathrm{p}<0.001)$. WSW were more likely to drink more than $140 \mathrm{~g}$ of alcohol per week but this difference was not statistically significant (table $1)$.

On multivariate analysis, current or previous injecting drug use was strongly associated with WSW (OR 5.0). 
EXCLUSIVE WSW NON-SEXUAL RISK BEHAVIOUR As with the whole group of WSW, the reported rate of ever injecting drugs was very high at $22 \%$ and significantly higher than controls. Sex work was significantly more common in exclusive WSW compared with controls (16\% versus $11 \%$, OR $1.6, \mathrm{p}=0.039$ ).

Although overall rates of smoking were not different between exclusive WSW and controls, the exclusive WSW were significantly more likely to be heavy smokers ( $17 \%$ versus $11 \%$, OR 1.6, $\mathrm{p}=0.007$ ).

\section{Discussion}

This study presents data on over 1400 WSW attending a public urban sexual health centre in Australia. To our knowledge, it is the largest cross sectional study on WSW. In common with published data, our study demonstrated significant differences in prevalence of certain STIs and blood borne viruses in WSW and women who do not report sex with women.

The demographic characteristics of the WSW were different from those of controls: WSW were more likely to be born in Australia, speak English as their first language, and identify as Aboriginal or Torres Strait Islander. We did not match cases and controls for ethnic background and this difference may be a potential source of confounding in our study.

In line with previous studies, ${ }^{11-13}$ the prevalence of BV in WSW was significantly greater than in controls, and this remained significant after multivariate analysis. However, the proportion of WSW diagnosed as having BV $(8 \%)$ was much less than that detected by Skinner et $a l^{11}$ and Edwards and Thin, ${ }^{12} 33 \%$ and 36\% respectively. This in part may be explained by the fact that one third of the study subjects did not have a genital screen on their first visit to the centre, and that women may leave the clinic before Gram stain results are finalised, especially if they are free of symptoms (which is true of $50 \%$ of women with $\left.\mathrm{BV}^{14}\right)$. In the latter case a $\mathrm{BV}$ diagnosis is not always documented in the file under the first visit. Also, WSW were significantly less likely to present with genital symptoms. Thus, differential measurement bias may have occurred, and the prevalence of $\mathrm{BV}$ in WSW may have been underestimated to a greater extent than in controls. The odds ratio for BV detection on cervical cytology was greater than for clinically diagnosed BV, which supports the suggestion of differential measurement error occurring.

The reasons behind the higher prevalence of BV in WSW are unclear. Potential for sexual transmission remains disputed..$^{13}$ Sexual practices in woman to woman sex have been implicated and in a recent study ${ }^{16}$ more frequent episodes of receptive oral sexual intercourse were independently associated with BV. We acknowledge that our study is limited by lack of data on specific female-female sexual practices.

The viral STIs, herpes simplex, and genital warts were common diagnoses in both WSW and controls, and new diagnoses were also demonstrated in exclusive WSW. WSW were less likely to have genital warts at clinic presen- tation. Paradoxically WSW were significantly more likely to report a history of genital warts. This could not be explained by an age effect.

Prevalence of Trichomonas vaginalis (TV) was low in both WSW and controls. Woman to woman transmission of TV has been well documented. ${ }^{11} 121718$ Of the five WSW who were diagnosed with TV, one was an exclusive WSW, but her regular partner did not demonstrate TV on wet film.

Historically, WSW have often been discouraged from attending for cervical cytology because of a perceived low risk of abnormality. Published studies have refuted this belief and clearly demonstrate presence of the spectrum of cervical cytology atypias in WSW, including women with no history of male partners. ${ }^{19-22}$ We demonstrated that WSW have a similar prevalence of cervical atypias to women with no history of sex with women, confirming Marrazzo et al's study in the USA. ${ }^{19}$

Very few of the women in the study were HIV positive, and there was no significant difference between WSW and controls. The risk of sexual transmission of HIV between women, although unknown, is thought to be low. However, our study demonstrates that WSW are more likely than non-WSW to engage in recognised HIV risk behaviours such as IDU, sex work, sex with a bisexual man, and sex with a man who injects drugs, confirming previous reports. ${ }^{4} 6723$ Behavioural research also demonstrates that a woman's sexual identity is not an accurate predictor of behaviour, with a large proportion of "lesbian" women reporting sex with (often high risk) men. ${ }^{24}{ }^{25}$ Only $7 \%$ of our WSW sample had never had sexual contact with a male.

Almost $25 \%$ of our WSW reported current or previous injecting drug use. This confirms previous studies that demonstrate high rates of substance abuse in WSW. ${ }^{72425}$ All 73 of the HCV positive WSW were IDUs. Four of the five WSW who were HIV positive reported previous or current injecting drug use.

Women drug injectors who have sex with women appear to be at higher risk for HIV than other IDUs ${ }^{26-29}$ and an independent association between female to female sex and HIV positivity has been reported. ${ }^{27}$ The reasons for this are unclear, but may be related to stigmatisation from non-WSW IDUs and non-IDU WSW. ${ }^{30}$ Young WSW appear at particularly high risk. ${ }^{31}$ In 1998, an Australia-wide survey of "same sex attracted young people" reported an IDU rate of $15 \%$ in same sex attracted young women (age 14-21). In contrast, $7 \%$ of the males and less than $5 \%$ in non-same sex attracted young people reported injecting drug use. ${ }^{32}$

After multivariate analysis, the most strongly associated WSW features were bacterial vaginosis, self injecting drug use, a sexual partner who injects drugs, a homo/bisexual male sexual partner, no male sexual partners in the past year and, more than 50 lifetime male sexual partners.

Our study is limited by the use of a clinic population which may not be representative of the WSW in the general community. In addition, one third of our study population 
were not screened for STIs. We also lacked data on specific female to female sexual practices and sexual identity. Despite these limitations, to our knowledge, this is the largest published study of STIs and behavioural risk factors in WSW.

We have demonstrated an increased prevalence of hepatitis $\mathrm{C}$ and $\mathrm{BV}$, similar rates of abnormal cervical cytology, and a higher prevalence of sexual and non-sexual risk taking behaviour in WSW compared with nonWSWs. These data argue strongly for increased measures to improve our understanding of the sexual health of WSW. There is a pressing need for basic research into STI/HIV transmission dynamics and behavioural research of WSW, as well as targeted intervention strategies for both sexual and non-sexual risk taking behaviour.

The authors are very grateful to Chris Mangioni for her assistance with data entry and literature appraisal and to Megan Nicholson for her review of the manuscript and contributing to the literature search. We are also grateful to the Sydney Sexual Health Centre, Richard Rohrsheim in particular, for access to the database and to Robin Tideman for her assistance with the

Contributors: KF, study concept and design, data analysis and writing of manuscript; CE, study design and assisted with data interpretation and editing of manuscript; CM, data analysis and editing of manuscript; AM, editing of manuscript.

1 Committee on Lesbian Health Research Priorities, Institute of Medicine. In: Solarz AL, ed. Lesbian health: current assessment and directions for the future. Washington DC: National Academy Press, 1999

2 Centers for Disease Control and Prevention. Report on lesbian HIV issues meeting. April 20-21, 1995.

3 Holmes KK, Sparling PF, Mardh P, et al. Sexually transmitted diseases. 3rd ed. New York: McGraw Hill, Health ted diseases. 3rd ed. New
Professions Division, 1999.

4 Bevier PJ, Chiasson MA, Heffernan RT, et al. Women at a sexually transmitted disease clinic who reported same-sex contact: their HIV seroprevalence and risk behaviours. $A m$ f Public Health. 1995;85:1366-71.

5 Magura S, O'Day J, Rosenblum A. Women usually take care of their girlfriends: bisexuality and HIV risk among intravenous drug users. F Drug Issues 1992;22:179.

6 Cohen H, Marmor M, Wolfe H, et al. Risk assessment of HIV transmission among lesbians. $\mathcal{F}$ Acquir Immune Defic Syndr 1993;6:1173-4

7 Lemp GF, Jones M, Kellogg TA, et al. HIV seroprevalence and risk behaviours among lesbians and bisexual women in San Francisco and Berkeley, California. Am f Public Health 1995;85:1549-52.

8 Giacomini G, Calcinai A, Moretti D, et al. Accuracy of cervical/vaginal cytology in the diagnosis of bacterial vaginosis. Sex Transm Dis 1998;25:24-7.

9 SPSS: Statistical package for the social sciences (computer program). Version 7.9. Chicago, IL: SPSS Inc, 1995.
10 SAS System Windows Version 6.12 (computer program). Cary, NC: SAS Institute Inc, 1989-96.

11 Skinner CJ, Stokes J, Kirlew Y, et al. A case-controlled study of the sexual health needs of lesbians. Genitourin Med 1996;72:277-80.

12 Edwards A, Thin RN. Sexually transmitted diseases in lesbians. Int f STD AIDS 1990;1:178-81.

13 Berger BJ, Kolton S, Zenilman JM, et al. Bacterial vaginosis in lesbians: a sexually transmitted disease. Clin Infect Dis $1995 ; 21: 1402-5$

14 Schwebke JR, Hillier SL, Sobel JD, et al. Validity of the vaginal gram stain for the diagnosis of bacterial vaginosis. Obstet Gynecol 1996;88:573-6.

15 McCaffrey M, Varney P, Evans B, et al. Bacterial vaginosis in lesbians: evidence for lack of sexual transmission. Int $\mathcal{F}$ STD AIDS 1999:10:305-8.

16 Schwebke JR, Richey CM, Weiss HL. Correlation of behavours with microbiological changes in vaginal flora. 7 Infect Dis 1999;180:1632-6.

17 Kellock DJ, O'Mahony CP. Sexually acquired metronidazole-resistant trichomoniasis in a lesbian couple. Genitourin Med 1996;72:60-2.

18 Sivakumer K, De Silva AH, Basu Roy R. Trichomonas vaginalis infection in a lesbian. Genitourin Med 1989;65:399400 .

19 Marrazzo JM, Koutsky LA, Stine KL, et al. Genital human papillomavirus infection in women who have sex with women. F Infect Dis 1998;178:1604-9.

20 O'Hanlan KA, Crum CP. Human papillomavirusassociated cervical intraepithelial neoplasia following lesbian sex. Obstet Gynecol 1996;88:702-3.

21 Ferris DG, Batish S, Wright TC, et al. A neglected lesbian health concern: cervical neoplasia. F Fam Practice 1996;43: $581-4$.

22 Council on Scientific Affairs, American Medical Association. Health care needs of gay men and lesbians in the United States. $7 A M A$ 1996;275:1354-9.

$23 \mathrm{Kral}$ AH, Lorvick J, Bluthenthal RN, et al. HIV risk profile of drug-using women who have sex with women in 19 United States cities. Int 7 AIDS Hum Ret 1997;16:211-17.

24 Richters J, Lubowitz S, Bergin S, et al. HIV risks among women in contact with Sydney's gay and lesbian community. Venereology 1998;11:35-8.

25 Alley J, Alwood K, eds. The lesbian information project. The LIP Report: Lesbians and HIV/AIDS. Sydney, 1993.

26 Friedman S. Women drug injectors who have sex with women: heightened risk and unknown reasons suggest the need for further research. Int AIDS Soc Newsletter 1998;11: $12-13$.

27 Jose B, Friedman SR, Curtis R, et al. Syringe mediated drug-sharing (backloading): a new risk factor for HIV among injecting drug users. AIDS 1993;7:1653-60.

28 Ross M, Wodak A, Gold J, et al. Differences across sexual orientation on HIV risk behaviours in injecting drug users. AIDS Care 1992:4:139-48.

29 Friedman SR, Jose B, Deren S, et al. Risk factors for HIV seroconversion among out-of-treatment drug injectors in high and low seroprevalence cities. Am f Epidemiol 1995;142:864-74.

30 Piot P, Aggleton P. AIDS, inequality and prevention. Int AIDS Society Newsletter 1998;10:8-10.

31 Faulkner $\mathrm{AH}$, Cranston K. Correlates of same-sex sexual behaviour in a random sample of Massachusetts high school students. Am 7 Public Health 1998;88:262-6.

32 Hillier L, Dempsey D, Harrison L, et al, eds. A national report on the sexuality, health and well-being of same-sex attracted young people. La Trobe University: Australian Research Centre in Sex, Health and Society, 1998. 